\title{
Column aerosol characterization in a semi-arid region around Marrakech during the WATERMED 2003 campaign
}

\author{
J. L. GÓMEZ-AMO*†, V. ESTELLÉS†, R. PEDRÓS $\dagger$, M. P. UTRILLAS $\dagger$, \\ J. A. SOBRINO \\ $\uparrow$ Solar Radiation Group, Departament de Física de la Terra i Termodinàmica, \\ Universitat de València, Spain \\ łGlobal Change Unit, Departament de Física de la Terra I Termodinàmica, Universitat \\ de València, Spain
}

(Received 28 November 2006; in final form 4 December 2007)

\begin{abstract}
In the framework of the WATERMED (WATer use efficiency in natural vegetation and agricultural areas by Remote sensing in the MEDiterranean basin) project, an experimental field campaign was carried out in a semi-arid region near Marrakech, Morocco, during March 2003. This work focused on the columnar aerosol characterization from spectroradiometric and photometric measurements of direct solar irradiance and sky radiance at ground level. The results show a high dependence of the aerosol optical properties on the air masses present in the area. Two periods with different aerosol loads were observed in the campaign. In the first, Atlantic-origin aerosols showed a marine particle accumulation mode combined with a dominant mode corresponding to coarse particles of local origin. In the second period the synoptic situation changed towards a Saharan + Atlantic origin, the Atlantic influence persisting at altitude while at lower levels the presence of air masses proceeding from the Saharan desert was observed. This dry air carried a large quantity of mineral particles that increased the area's turbidity, leading to a substantial increase in the volume of the whole distribution, a displacement of the accumulation mode radius towards higher values and an increasingly evident spread of the coarse particle mode, although the radius remained the same as that in the first period of the campaign.
\end{abstract}

\section{Introduction}

In recent years, research on water use efficiency and water management focusing on water saving, particularly in agriculture, has become a priority topic in the European Union's Research Programme (see, for instance, http://cordis.europa.eu or references to FP6). The WATERMED (WATer use efficiency in natural vegetation and agricultural areas by Remote sensing in the MEDiterranean basin) project, which was supported by the European Union over 4 years (2000-2004), sought to identify drought-prone areas and the evolution of ecotones through the combined use of historical and space-based remotely sensed data, vegetation models and field measurements. In this context, the region around Marrakech was chosen for detailed study of the water use efficiency by means of field measurements and high resolution imagery.

In March 2003 an intensive campaign was carried out by participants from institutes from four different countries: the University of Valencia, Spain, the

\footnotetext{
*Corresponding author. Email: jlgomeza@uv.es
} 
Institute Nacional de la Reserche Agronomique and the Centre d'Etudes Spatiales de la Biosphere (CESBIO) from France, the Universite Cady Ayyad from Morocco and the National Authority for Remote Sensing and Space Sciences (NARSS) from Egypt. The objectives of the campaign were focused on thermal infrared measurements as well as measurements of evapotranspiration and angular measurements. Coinciding with the field measurements, satellite data including AVHRR (Advanced Very High Resolution Radiometer), AATSR (Advanced Along-Track Scanning Radiometer), LANDSAT and MODIS (MODerate resolution Imaging Spectroradiometer) were also acquired.

As atmospheric aerosols are the principal cause of uncertainty in atmospheric correction models, the main task of the Solar Radiation Group of the University of Valencia was to characterize the spectral solar irradiance and to describe the columnar properties of some atmospheric constituents (aerosols, ozone and water vapour) in order to reduce this uncertainty. Season and location are only partial predictors of aerosol optical properties. Aerosol size, for instance, can vary significantly from day to day at a single location (Holben et al. 1996, Remer and Kaufman 1998). Such day-to-day variations may stem from meteorological variability rather than direct changes in the strength of aerosol sources so the use of experimental atmospheric data becomes more important in areas with great atmospheric variability. In these cases a daily mean value of the aerosol properties does not really represent the whole day and it is better to use instantaneous values at the same time as other statistical parameters. Such is the case in the region studied in this work, where large variations in the aerosol burden are often found, depending on the air mass influence (Atlantic or desert).

However, in African countries there are usually no permanent ground-based stations for atmospheric measurements and it is difficult to obtain long data series to characterize the aerosol behaviour. Furthermore, the aerosol models of desert particles do not work very well because the microphysical properties of mineral particles are not well characterized because of their irregular shape (Mishchenko et al. 2000, IPPC 2001, Sinyuk et al. 2003). In these areas satellite measurements can be affected by errors due to validation deficiencies.

The Iberian Peninsula is seriously affected by continuous Saharan particle intrusion events causing a significant increase in the atmospheric turbidity, especially in central and southern regions. For this reason there is considerable interest in knowing the experimental properties of desert aerosol and their roles in synoptic transport in order to determine the way these particles arrive over the Iberian Peninsula and how they affect the meteorological conditions.

In this paper we present the results corresponding to the column integrated aerosol properties over the Marrakech region during this WATERMED campaign, with particular emphasis on the spectral optical depth, the values obtained for the Ångström wavelength exponent and the aerosol size distribution and its relationship to the origin of the air masses over the measurement site.

\section{Site description, instrumentation and measurements}

\subsection{Site description}

The region of Marrakech-Tensif-Al Haouz, where the WATERMED 2003 measurement campaign was performed, covers seven provinces and extends over a total area of $31827 \mathrm{~km}^{2}$. The test region for the project was the catchment of Oued 


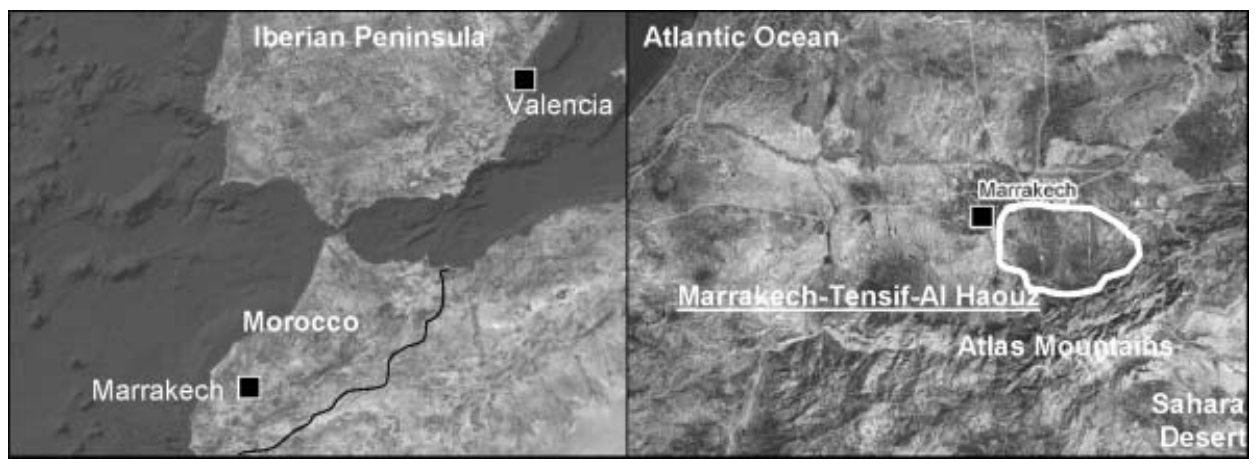

Figure 1. Location of the study area (delimited with a white line) in the Oued Tensif water catchment $\left(31.658^{\circ} \mathrm{N}, 7.608^{\circ} \mathrm{W}, 586 \mathrm{~m}\right.$ asl) in Marrakech (Morocco) and the reference station at Burjassot $\left(39.508^{\circ} \mathrm{N}, 0.418^{\circ} \mathrm{E}, 60 \mathrm{~m}\right.$ asl) in Valencia (Spain).

Tensift, which is located $50 \mathrm{~km}$ west of Marrakech city (see figure 1). This is an area of irrigated agriculture over an area of some $2800 \mathrm{~km}^{2}$ divided into agricultural parcels with an average size of 3 ha that require high resolution satellite imagery to be discerned. Seventy per cent of the surface area is dedicated to wheat, while the remaining area is uncultivated and generally corresponds to clay soils. The region is very flat and homogeneous except to the south, where some $60 \mathrm{~km}$ away rise the Atlas Mountains, whose maximum elevation is $4165 \mathrm{~m}$. The Atlas Mountains act as an orographic barrier separating the region from the Sahara desert, which begins just to the southeast of the mountain range.

According to Köppen's climate classification (Köppen 1918), the region around the city of Marrakech has a dry and arid climate (Gómez-Amo 2006), with irregular rainfall with an annual average of $240 \mathrm{~mm} /$ year. In the summer months the average temperature is around $37.7^{\circ} \mathrm{C}$, while in winter it is $4.9^{\circ} \mathrm{C}$. The low rainfall contrasts with the average annual evapotranspiration ( $2400 \mathrm{~mm} /$ year $)$, implying that it is an area with a potentially high water deficit.

We used another (Mediterranean) measurement station located in Burjassot (Valencia, Spain), for which measurements from 2002 to 2005 are available, for comparison. This station is described in detail elsewhere (Estellés 2006). The aerosols found in this region are generally industrial, continental and maritime, with a noted influence of Saharan dust particles during the summer months, as the station is located only $5 \mathrm{~km}$ from the city of Valencia $(1.5$ million inhabitants in the metropolitan area) and $10 \mathrm{~km}$ from the Mediterranean Sea.

\subsection{Instrumentation}

To perform the solar irradiance measurements we used three different instruments: a Licor-1800 spectroradiometer and two photometers, a Cimel-CE318 and a Microtops II. The results were also compared with the values provided by the MODIS instrument.

2.2.1 The Licor Li-1800 spectroradiometer. This spectroradiometer has a simple monochromator and a holographic grating with 600 grooves $/ \mathrm{mm}$ and a 300 $1100 \mathrm{~nm}$ spectral range. The optical receiver is a Teflon dome with a $2 \pi$ steradian field of view (FOV). The bandwidth (full width at half maximum, FWHM) of the 
instrument is $6 \mathrm{~nm}$ and the bandpass precision is $1 \mathrm{~nm}$. The detector is a silicon photodiode operating in photovoltaic mode. This instrument is used to measure the spectral solar irradiance (global and direct components) and to retrieve indirectly the spectral Aerosol Optical Depth (AOD). It is deployed on a tripod with three ball-socket joints that allow rotation around three axes. For the measurements of direct irradiance a collimator tube is used with a $4.6^{\circ}$ FOV fitted with an alignment system that couples directly to the optical receiver. The uncertainty associated with this instrument in the working spectral range $(340-1020 \mathrm{~nm})$ is $5 \%$ and the calibration characteristics and its corrections can be found elsewhere (Martínez-Lozano et al. 2003, Gómez-Amo 2006).

2.2.2 The Cimel CE318 sunphotometer. The Cimel CE318 is the standard automatic photometer used by the AERosol RObotic NETwork (AERONET; Holben et al. 1998) for measuring direct solar and sky radiance. The scan of each series of five channels lasts only $8 \mathrm{~s}$, although three direct measurement cycles are taken $20 \mathrm{~s}$ apart for cloud discrimination and variability estimation. The instrument consists of a sensor head equipped with a filter wheel with eight interferential filters. A twin collimator tube with a $1.2^{\circ} \mathrm{FOV}$ is attached to the double-windowed sensor head to measure sun and sky radiance with two separate $\mathrm{Si}$ photodiodes. It has five channels centred nominally at the wavelengths 440, 670, 870,940 and $1020 \mathrm{~nm}$, each with an FWHM of $10 \mathrm{~nm}$. The Cimel automatically points at the sun following a detailed time-plan, driven by a partially userprogrammable electronic control box. The calibration techniques applied to this instrument and its corrections can be found elsewhere (Shaw 1983, Estellés 2006, Estellés et al. 2007).

2.2.3 The Microtops II photometer. The Microtops II is a handheld photometer that operates in five channels $(305.5,312.5,320,940$ and $1020 \mathrm{~nm})$ and is capable of directly providing the total amount of ozone, the precipitable water vapour content and the AOD at $1020 \mathrm{~nm}$ in the whole atmospheric column. The first three channels are for measuring ozone, the $940 \mathrm{~nm}$ channel is for precipitable water vapour and the $1020 \mathrm{~nm}$ channel for AOD measurement. Each of these channels has a collimator with a $2.5^{\circ} \mathrm{FOV}$ and deflectors to remove internal reflections. Furthermore, it incorporates a narrow-band interferential filter and a photodiode tailored to each band. The calibration procedure and a detailed characterization of the instrument uncertainties can be found in Morys et al. (2001) and Estellés et al. (2003).

2.2.4 MODIS. The MODIS instrument is onboard the Terra (EOS AM) and Aqua (EOS PM) satellites. Terra's orbit around the Earth is timed so that it passes from north to south across the equator in the morning, whereas Aqua passes south to north over the equator in the afternoon. Terra MODIS and Aqua MODIS are viewing the entire Earth's surface every 1 to 2 days, acquiring data in 36 spectral bands. The MODIS Aerosol Product (Remer et al. 2005) monitors the ambient AOD over the oceans globally and over a portion of the continents.

The aerosol products available from MODIS over land include AOD at three visible wavelengths $(470,550$ and $660 \mathrm{~nm})$ and several derived parameters. Over the ocean, the AOD is provided in seven wavelengths from 470 to $2130 \mathrm{~nm}$. In this work we used the MODIS data only to obtain the AOD in three different bands (470, 550 and $660 \mathrm{~nm}$ ) over the duration of the campaign. 


\subsection{Measurements plan}

The WATERMED campaign was carried out during 3-17 March 2003. The instruments were deployed on a terraced roof of a rural building. The measurements plan for the LICOR included half-hourly measurements from 0800 to $1600 \mathrm{~h}$ UTC. During the $30 \mathrm{~min}$ before and after a satellite overpass, the measurement frequency was increased to $5 \mathrm{~min}$. The Microtops II measurements were made at the same time. Measurements were only made under clear sky conditions so only 8 of the 15 days allowed aerosol characterization. For the CIMEL sunphotometer, the standard measurement schedule from AERONET was used with extra measurements at the time of satellite overpasses.

\section{Methodology}

\subsection{AOD}

The AOD is the most simple and powerful parameter used to characterize aerosols. It can be obtained as the immediate result of solar radiation extinction measurements by using the Bougher-Lambert-Beer law and eliminating the contribution of the gaseous components in the relevant spectral range. In the considered spectral interval the only components that show appreciable absorption are ozone (Chappuis band), $\mathrm{NO}_{2}$ and water vapour. Thus AOD is represented by $k_{\mathrm{a}}(\lambda)$ and can be expressed as:

$$
k_{\mathrm{a}}(\lambda)=k_{\mathrm{T}}(\lambda)-k_{\mathrm{R}}(\lambda)-k_{\mathrm{O}_{3}}(\lambda)-k_{\mathrm{w}}(\lambda)-k_{\mathrm{NO}_{2}}(\lambda)
$$

where $k_{\mathrm{T}}(\lambda)$ is the optical depth of the atmosphere, $k_{\mathrm{R}}(\lambda)$ is the optical depth contribution due to molecular scattering (Rayleigh scattering) and $k_{\mathrm{O}_{3}}(\lambda), k_{\mathrm{w}}(\lambda)$ and $k_{\mathrm{NO}_{2}}(\lambda)$ are the optical depths due to the absorption of ozone, water vapour and nitrogen dioxide, respectively.

To determine the total atmospheric optical depth the extraterrestrial spectrum proposed by the SMART2 model (Gueymard 2001) was used after smoothing for the Licor 1800 bandwidth. The optical mass was obtained from the empirical relationship proposed by Kasten and Young (1989). The contribution due to Rayleigh scattering was calculated using the approximation of Bodhaine et al. (1999). The coefficients used for the ozone absorption were those proposed by Anderson and Mauersberger (1992), and the expressions and coefficients used to calculate the water vapour and $\mathrm{NO}_{2}$ absorption were taken from the SMART2 model (Gueymard 2001), although the amounts of this latter gas were almost negligible because of the rural nature of the measurement site. Finally, water vapour and ozone measurements were also made with the Microtops II.

To determine the error in the AOD from spectroradiometer measurements, Utrillas (1995) propose a simplified method. This method is similar to that developed by Russell et al. (1993) and Schmid et al. (1997). The authors have previously used this method to calculate the errors with experimental measurements made at several other sites (Pedrós et al. 2003, Gómez-Amo et al. 2006), where, in summary, the measurement of the error in the AOD was mainly conditioned by the error in the measurement of the direct spectral irradiance and the value of the optical air mass at the time of the measurement.

The Ångström parameters $(\alpha, \beta)$ were calculated using the $\log -\log$ fit of the experimental AOD values against the wavelength following the Ångström law: 


$$
k_{\mathrm{a}}(\lambda)=\beta \lambda^{-\alpha}
$$

where the coefficient $\beta$, known as the turbidity coefficient, represents the atmospheric aerosol content (and is equal to $k_{\mathrm{a}}(\lambda)$ at $1000 \mathrm{~nm}$ ) and is related to the aerosol load, while $\alpha$ is the Ångström wavelength exponent that represent the slope of equation (2) and is related to the size of the particles. If the value of $\alpha$ is greater than 1.5, the small particles are observed to be more important for the scattering phenomena. Otherwise, if $\alpha$ is less than 1.0, the scattering is mainly produced by the largest aerosols (Van der Hulst 1957). This last parameter has been the subject of numerous studies in relation to its application in remote sensing because many satellite-based and ground-based measurements provide retrievals of spectral AOD but not often direct size distribution retrievals. A detailed description of the methodology used with the Li-Cor and Cimel instruments can be found in Gómez-Amo et al. (2006) and Estellés (2006), respectively.

\subsection{Size distribution}

The aerosol size distribution of the atmospheric aerosols can be formulated in terms of a Fredholm integral equation of the first kind (Yamamoto and Tanaka 1969) obtained from the Mie theory. The aerosol size distribution can be retrieved from the shape of the spectral AOD curve by solving the equation:

$$
k_{\mathrm{a}}(\lambda)=\int_{0}^{r} \pi r^{2} Q_{\mathrm{ext}}(r, \lambda, m) n_{\mathrm{c}}(r) \mathrm{d} r
$$

where $Q_{\text {ext }}(r, \lambda, m)$ is the Mie extinction efficiency factor, $m$ is the complex refraction index and $n_{\mathrm{c}}(r)$ represents the number of particles per unit radius and unit area contained in the total atmospheric column. The inversion of equation(3) is an example of a multiple solution problem where $Q_{\text {ext }}(r, \lambda, m)$ is the kernel and $n_{\mathrm{c}}(r)$ is the function to be found. To solve equation (3) we can apply two inversion methods depending on the available measurements. The first is applied using only extinction measurements through the inversion algorithm proposed by King et al. (1978) and King (1982), whereas the second method also needs sky radiance measurements with the skyrad.pack code (Nakajima et al. 1996). The latter can only be applied when sky radiance measurements are available. Other aerosol properties can also be obtained from the radiance measurements if the skyrad.pack is applied. In our case version 4.2 was used, which allows the retrieval of size distribution, effective radius, complex refractive index, single scattering albedo, and the asymmetry parameter. More details on the application of the code to these kinds of data can be found in Estellés (2006).

Once the size distribution has been obtained, the function can be represented as a function of particle radius and a fit made assuming that each of the modes follows a log-normal function behaviour of the type:

$$
\frac{\mathrm{d} V}{\mathrm{~d} \log r}=\frac{V_{0}}{\sqrt{2 \pi} \log \sigma} \exp \left[-\frac{1}{2}\left(\frac{\log r-\log r_{\mathrm{m}}}{\log \sigma}\right)^{2}\right]
$$

From the mentioned fit we obtained the modal parameters $V_{0}, r_{\mathrm{m}}$ and $\sigma$, where $V_{0}$ is the maximum particle concentration, $r_{\mathrm{m}}$ is the radius of the mode and $\sigma$ is the standard deviation. 


\section{Results and discussion}

\subsection{Experimental $A O D$}

The complete analysis of the AOD was based on its spectral behaviour, using the LiCor measurements, and the change in value for different wavelengths (440, 500, 870, $1020 \mathrm{~nm}$ ) comparing the Li-Cor and Cimel measurements. To represent the evolution of the AOD during the campaign, figure 2 shows its value at $440 \mathrm{~nm}$. In this figure it is possible to identify two different periods with respect to the turbidity. The first, between 5 March and 11 March 2003, is characterized by fairly low values of AOD, with an average value of 0.12 at $440 \mathrm{~nm}$. In the second period, between 13 March and 15 March 2003, a notable increase in AOD was observed with an average value reaching 0.38 at $440 \mathrm{~nm}$ and which also showed a greater daily variability.

In general, the AOD values observed through the campaign were lower than we expected because of the proximity of the Sahara Desert. We compared these unexpected results with satellite results although we recognize that this comparison cannot be considered as a statistical analysis because it is limited to the period of the campaign. Nevertheless, it could help to establish the aerosol trends over this short period. Table 1 compares the instantaneous AOD values at $550 \mathrm{~nm}$ obtained with the Li-Cor, the Cimel and from MODIS. For the Cimel the values of the AOD at $550 \mathrm{~nm}$ were obtained by adjusting the spectral AOD values using an Ångström-type potential function. The gaps in the table correspond to the days for which measurements were not available for each instrument. The table shows that, when the turbidity was low, the MODIS values were slightly higher than those for the ground-based instruments whereas the reverse occurred when the turbidity increased. In all cases the trend observed for MODIS was similar to that obtained with the ground-based instruments, with a notable increase during the final days of

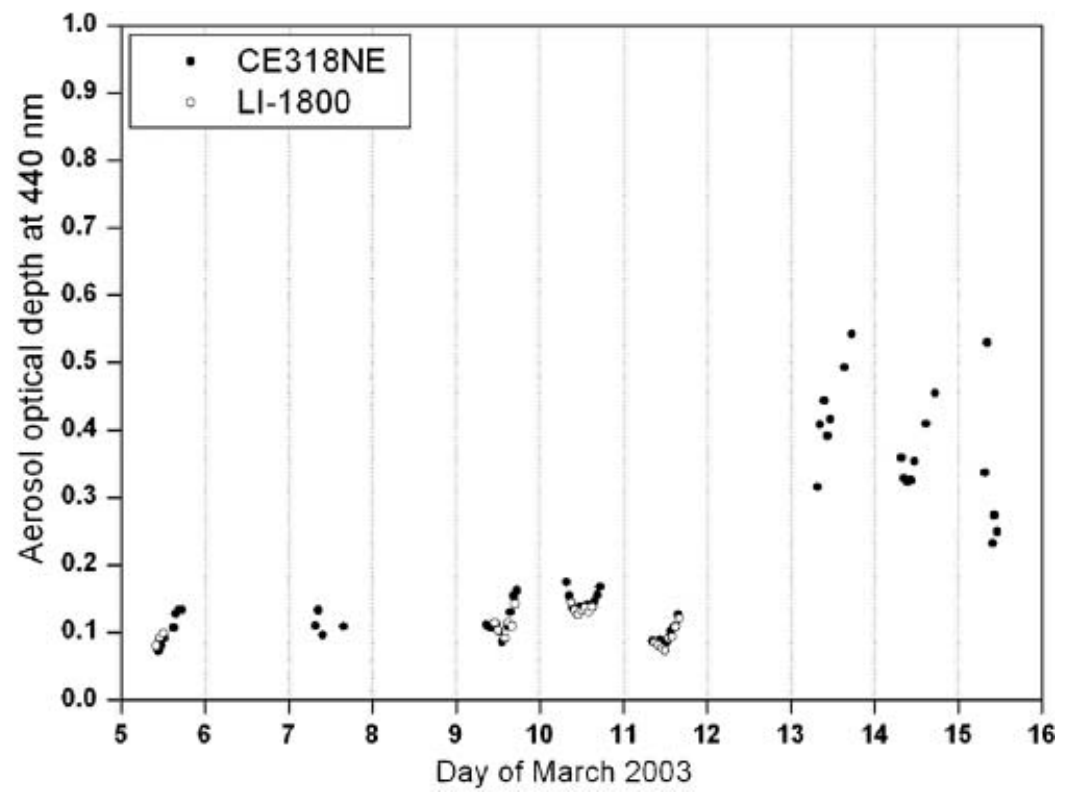

Figure 2. AOD at $440 \mathrm{~nm}$ during the WATERMED campaign from Li-Cor and Cimel measurements. 
Table 1. Comparison of the AOD at $550 \mathrm{~nm}$ for the MODIS, Li-Cor and Cimel instruments.

\begin{tabular}{lcccc}
\hline Date & Time $(\mathrm{h})$ & MODIS & Li-Cor & Cimel \\
\hline 5 March 2003 & 1045 & 0.091 & $0.07 \pm 0.03$ & $0.06 \pm 0.02$ \\
6 March 2003 & 1125 & 0.215 & & $0.07 \pm 0.02$ \\
7 March 2003 & 1030 & 0.061 & & \\
8 March 2003 & & & $0.08 \pm 0.03$ & $0.08 \pm 0.02$ \\
9 March 2003 & 1155 & 0.098 & $0.10 \pm 0.03$ & $0.10 \pm 0.02$ \\
10 March 2003 & 1100 & 0.194 & $0.07 \pm 0.03$ & $0.08 \pm 0.02$ \\
11 March 2003 & 1145 & 0.113 & & \\
12 March 2003 & 1050 & 0.272 & & $0.41 \pm 0.02$ \\
13 March 2003 & 1130 & 0.383 & & $0.31 \pm 0.02$ \\
14 March 2003 & 1035 & 0.278 & & \\
15 March 2003 & 1120 & 0.325 & & \\
\hline
\end{tabular}

the campaign. The 6 and 12 March were days with abundant high clouds, which may account for the excessively high AOD provided by MODIS, possibly because of poor cloud filtering.

The spectral AOD over land and ocean by comparison with 2 years of AERONET measurements in different stations showed that the standard deviation of MODIS AOD retrievals fell within the predicted uncertainty. Usually this is within the interval \pm 0.03 to \pm 0.05 , with an average value of $2 \%$ (Chu et al. 2002 , Remer et al. 2002, 2005). In our case, in the WATERMED campaign, the standard deviation between the MODIS data and the photometric measurements was a little higher, reaching \pm 0.05 in both the Li-Cor and Cimel cases. The agreement between Li-Cor and Cimel AOD measurements has been studied previously and differences were always found to be less than $1 \%$ at all the wavelengths used except at $1020 \mathrm{~nm}$, where it could be up to $1.6 \%$ due to the temperature effect (Estellés 2006).

\subsection{Angström parameters}

The Ångström wavelength exponent $(\alpha)$ was obtained separately for each of the measurements by using equation(2) in the spectral interval $440-870 \mathrm{~nm}$. Figure 3 shows the evolution of the Ångström exponent over the campaign. As for the AOD, two distinct periods can be observed. In all cases the value of $\alpha$ showed values less than 1.0, indicating, in general, the presence of coarse particles playing an important role in the observed aerosol load in the area during the campaign. This is especially the case during the second part of the campaign, where $\alpha$ had an average value of 0.19 , whereas in the first period it was more variable and had an average value of 0.64 .

Figure 4 shows $\alpha$ in relation to the AOD at $870 \mathrm{~nm}$. A decreasing trend can be observed as the AOD at $870 \mathrm{~nm}$ increased. The highest AOD values corresponded to the lowest values of $\alpha$, indicating that the days with greatest turbidity were dominated by the presence of coarse-grained particles.

\subsection{Size distribution}

The aerosol size distribution was obtained using both the King and Nakajima methods. In the first case we assumed radii of 0.08 and $3.0 \mu \mathrm{m}$ for the integral limits and a complex refractive index of $1.40-0.0 \mathrm{i}$. In the second case the radius limits were extended from 0.05 to $15 \mu \mathrm{m}$ and the refractive index was obtained simultaneously. 


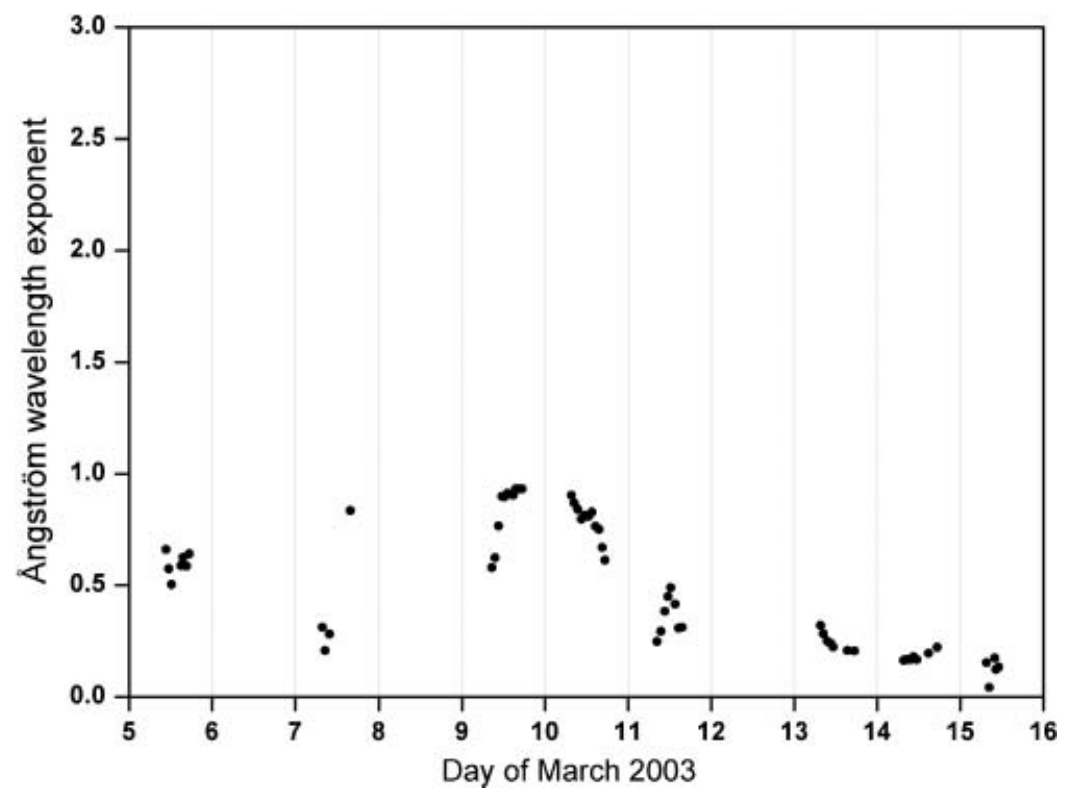

Figure 3. Ångström wavelength exponent during the WATERMED campaign.

Figure 5 shows the daily mean values of the aerosol size distribution retrieved using the Nakajima method expressed in terms of volume. In all of the cases analysed the curves possessed a clear three-mode form. An accumulation mode could be clearly seen although with a fair amount of variability during the campaign in terms of both volume and modal radius, together with two almost invariable coarse particle modes with radii centred at 1.7 and $7.1 \mu \mathrm{m}$, respectively. In general,

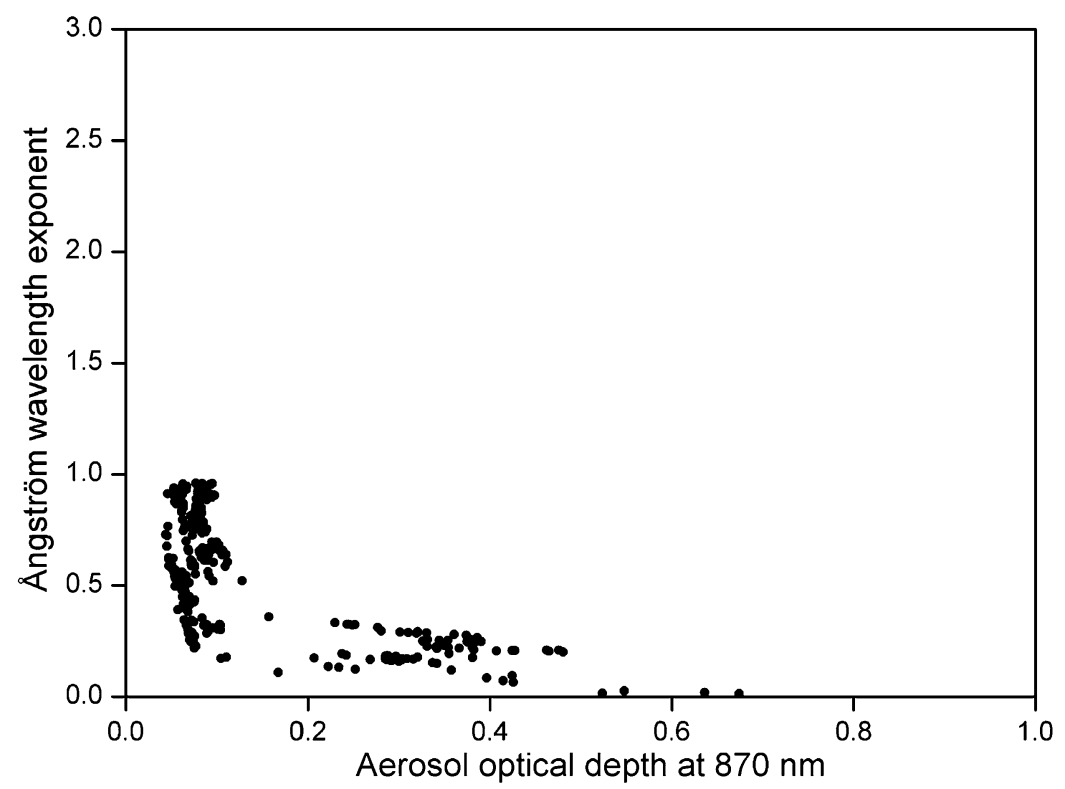

Figure 4. Ångström wavelength exponent versus AOD at $870 \mathrm{~nm}$ during the WATERMED campaign. 


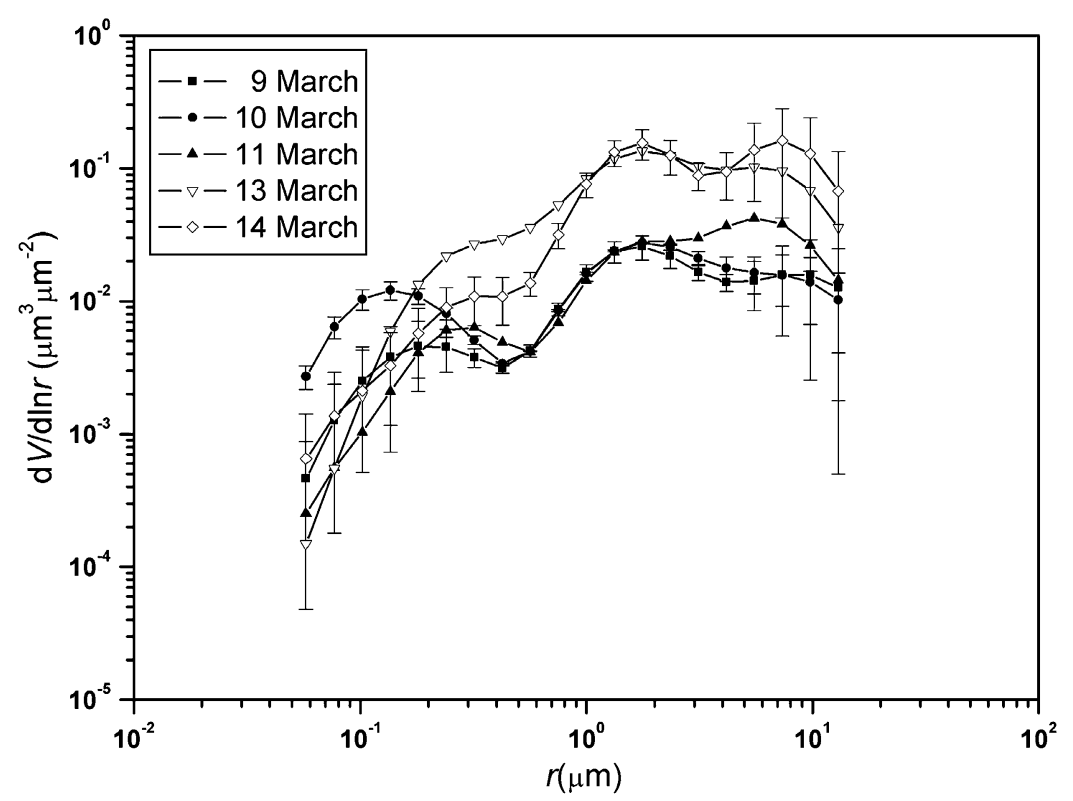

Figure 5 Daily aerosol size distribution retrieved using skyrad.pack version 4.2 for 9, 10, 11, 13 and 14 March 2003.

the coarse particles played a clearly dominant role in the size distribution, as had been suggested already by the low $\alpha$ value, which was below 1.0 at all times. The contribution per volume of the coarse particle mode was almost an order of magnitude higher than that observed for the accumulation mode. This situation was accentuated during the second part of the campaign (from 13 to 15 March), coinciding with the substantial increase in the AOD.

The variability observed in the size distribution was related fundamentally in the accumulation mode, with a displacement, between the first and the second period of the campaign, of the modal radius from 0.01 to $0.04 \mu \mathrm{m}$, at the same time that the modal volume increased. The radius of the coarse particles remained nearly constant while there was a dramatic growth in the volumes of both submodes. These differences between the two periods of the campaign were related to the entry of large particles, probably provoked by a change in the type of air masses over the region during the measurement campaign.

\subsection{Air mass back-trajectories}

To better describe the nature of the particles measured during the different periods of the campaign, the HYSPLIT4 (Hybrid Single-Particle Lagrangian Integrated Trajectory) model (Draxler and Rolph 2003) for computing the air mass backtrajectories arriving at a site at a given time was used. The trajectories calculated in this way give an indication of the path followed by the air mass and, therefore, what kind of particles they may carry. For each day, HYSPLIT 5-day back-trajectories were obtained at three different heights above ground: $500 \mathrm{~m}$ (within the boundary layer), $1500 \mathrm{~m}$ (near the transition between the boundary layer and the free atmosphere) and $3000 \mathrm{~m}$ (in the free atmosphere). Both the isentropic and the isobaric trajectories were examined to check the consistency of the calculated 
trajectories. Furthermore, the back-trajectories for three different times of a day were calculated to check the diurnal stability.

The 5-day back-trajectories showed the influence of an Atlantic-origin air mass at $3000 \mathrm{~m}$ that remained throughout the campaign. As also indicated by previously documented aerosol properties (AOD, $\alpha$ and size distribution), the back-trajectories revealed a significant change in the origin of the air masses arriving in the study region. The first air mass was characterized by a purely Atlantic influence rotating around Morocco before reaching the measurement zone (figure 6(a)). In the second period the Atlantic component at altitude combined with an air mass at lower heights proceeding from the interior of the African continent, which blew over the Saharan desert (figure $6(b)$ ). This air mass was probably loaded with mineral particles from the desert that provoked the marked increase in the AOD observed in figure 2. Thus, it can be considered that the Atlantic influence is characterized by low levels of atmospheric turbidity for which the particles are distributed in a clearly identified accumulation mode, with a radius centred at $1 \mu \mathrm{m}$, together with a coarseparticle mode in which a slight subdivision into two submodes can be seen with radii around 1.7 and $7 \mu \mathrm{m}$. The values observed for the Ångström exponent for this first period were too low to consider that the particles were exclusively of marine origin. For this reason, and given that the air masses remained some considerable time in the interior of Morocco before reaching the study zone, it is plausible to suggest that the characteristics of larger, local particles were added to the contribution from the marine particles leading to the spreading of the coarse-particle mode.

The arrival of air proceeding from the interior of the continent transported largersized particles that also increased the aerosol load and led to an increase in the accumulation mode radius, such that this radius seemed to disappear into the coarse-particle mode whereas in the latter the spreading into two modes became more evident, maintaining the modal radius of each.

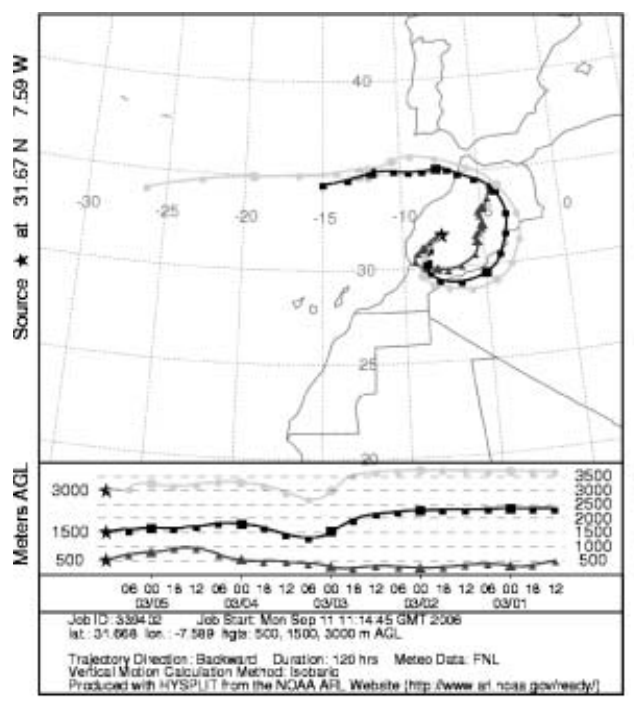

(a)

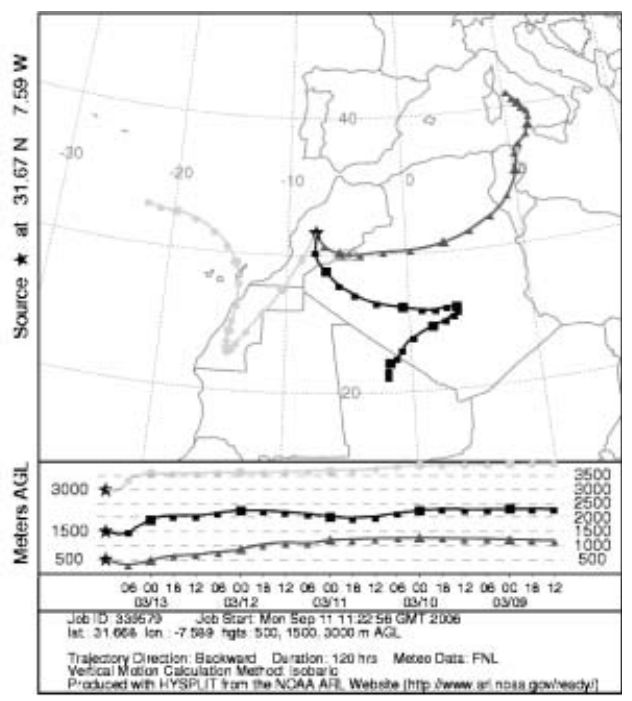

(b)

Figure 6. Five-day back-trajectories ending at the measurements site at 1200 GMT: (a) purely Atlantic air mass (5 March 2003); (b) Atlantic and Saharan air masses (13 March 2003). 


\subsection{Radiative parameters}

With the aim of obtaining additional information, various aerosol radiative parameters were analysed, including: the effective radius of the size distribution, the complex refractive index, the single scattering albedo and the asymmetry parameter. These parameters were obtained by applying the skyrad.pack code to the combined direct irradiance and sky radiance. A detailed summary of these parameters is shown in table 2. The table also shows the average values obtained for the city of Valencia during the same month for the same parameters as this measurement station has well-characterized aerosol properties corresponding to Saharan-origin air masses (Estellés 2006).

The parameters corresponding to the size distribution were obtained from lognormal fits of the distribution calculated using the King algorithm in which the third mode does not usually appear as it possesses a modal radius that is much higher than the upper limit used by the algorithm $(3 \mu \mathrm{m})$. For this reason, and to facilitate the comparison of the results obtained in Valencia in which habitually only two size distribution modes are observed, the accumulation and coarse modes (acc and coa respectively) only the characteristics corresponding to these two modes are shown in table 2. In this table it can be seen that the turbidity obtained in the first period of the WATERMED campaign was less than the average value for the month of March in Valencia. However, during the second period of the campaign the AOD experienced a marked increase, passing notably this average value obtained in Valencia. The behaviour of the Ångström exponent during the campaign always showed lower values than those observed in Valencia during March, indicating the importance of the coarse particles in the turbidity of the region around Marrakech for either of the synoptic situations analysed. Nevertheless, their importance was greater when the air masses came from the interior of the African continent and had passed over the Saharan desert whereas, in the case of Valencia, the turbidity was generally dominated by small particles whose origin was urban pollution. The same conclusion is obtained by analysing the effective radii, as they were clearly greater in

Table 2. Aerosol properties in the WATERMED campaign compared with the average monthly values in Valencia in March.

\begin{tabular}{|c|c|c|c|}
\hline & \multirow{2}{*}{$\frac{\text { Valencia }}{\text { March mean values }}$} & \multicolumn{2}{|c|}{ Marrakech } \\
\hline & & 5-11 March & 12-15 March \\
\hline AOD $(440 \mathrm{~nm})$ & $0.24 \pm 0.21$ & $0.12 \pm 0.03$ & $0.38 \pm 0.09$ \\
\hline AOD (500 nm) & $0.21 \pm 0.19$ & $0.11 \pm 0.03$ & $0.37 \pm 0.09$ \\
\hline$\alpha$ & $1.32 \pm 0.41$ & $0.64 \pm 0.22$ & $0.19 \pm 0.06$ \\
\hline$V_{\text {acc }}\left(\mu \mathrm{m}^{3} \mu \mathrm{m}^{-2}\right)$ & $0.19+0.28$ & $0.016+0.010$ & $0.04+0.04$ \\
\hline$V_{\text {coa }}\left(\mu \mathrm{m}^{3} \mu \mathrm{m}^{-2}\right)$ & $0.047 \pm 0.066$ & $0.07 \pm 0.04$ & $0.45 \pm 0.20$ \\
\hline$r_{\mathrm{acc}}(\mu \mathrm{m})$ & $0.059 \pm 0.065$ & $0.11 \pm 0.03$ & $0.60 \pm 0.50$ \\
\hline$r_{\text {coa }}(\mu \mathrm{m})$ & $1.7 \pm 0.36$ & $2.0 \pm 0.5$ & $4.0 \pm 2.0$ \\
\hline$\alpha_{\mathrm{ac}}$ & $3.10 \pm 1.6$ & $2.1 \pm 0.3$ & $2.58 \pm 1.10$ \\
\hline$\alpha_{\mathrm{coa}}$ & $2.13 \pm 0.60$ & $1.86 \pm 0.17$ & $2.55 \pm 0.64$ \\
\hline$r_{\mathrm{eff}}(\mu \mathrm{m})$ & $0.13 \pm 0.04$ & $1.10 \pm 0.17$ & $1.52 \pm 0.04$ \\
\hline$N$ & $1.39 \pm 0.04$ & $1.42 \pm 0.011$ & $1.45 \pm 0.008$ \\
\hline$M$ & $0.008 \pm 0.005$ & $0.014 \pm 0.002$ & $0.006 \pm 0.004$ \\
\hline$w_{0}$ & $0.92 \pm 0.05$ & $0.86 \pm 0.008$ & $0.91 \pm 0.03$ \\
\hline$g(\lambda)$ & $0.68 \pm 0.04$ & $0.75 \pm 0.013$ & $0.76 \pm 0.010$ \\
\hline$w\left(\mathrm{~g} \mathrm{~cm}^{-2}\right)$ & $1.29 \pm 0.54$ & $1.21 \pm 0.21$ & $0.97 \pm 0.8$ \\
\hline
\end{tabular}


Marrakech, taking values of 1.10 and $1.52 \mu \mathrm{m}$ for each of the two periods of the campaign, than the average value of $0.13 \mu \mathrm{m}$ in Valencia.

The real part of the refractive index was greater during the WATERMED campaign than the average value obtained in Valencia, increasing from 1.42 during the first part of the campaign up to 1.45 in the second period. The average value in Valencia was 1.39. This behaviour supports the idea of the presence of a higher quantity of dust particles in the region of Marrakech, especially during the second period of the campaign. However, the imaginary part of the refractive index and the single scattering albedo offer less certain results as no substantial differences were observed between the two sites. These parameters indicate the absorption capacity of the particles present in the atmosphere and, according to the values shown in table 2, it could be seen that this was slightly higher in Marrakech.

When the precipitable water vapour in the atmospheric column was considered, it was observed that, in general, the atmosphere was dryer in Marrakech. This was seen even more clearly during the second period of the campaign, when the water vapour content decreased from 1.21 to $0.97 \mathrm{~g} \mathrm{~cm}^{-2}$, which is consistent with the entry of a very dry Saharan-origin air mass loaded with large-sized mineral particles.

\section{Conclusion}

The atmospheric aerosols were characterized in the region around the city of Marrakech during the WATERMED campaign. The results show a great dependence of the aerosol optical properties with respect to the air masses present in the area. Two situations were analysed, the first corresponding to a dominant Atlantic influence at altitude that led to a clean atmosphere, with low turbidity and AOD values around 0.12 at $440 \mathrm{~nm}$. In this case, the aerosols presented an accumulation mode of marine particles, combined with a dominant coarse-particle mode of local origin, as the air masses at lower altitudes remained for a considerable time around the study zone. In the second situation the Atlantic influence appeared to persist at altitude while in the lower atmospheric layers the air masses arrived from the Saharan desert. This dry air transported a large quantity of mineral-origin particles that increased the turbidity in the area, reaching an AOD value of 0.38 at $440 \mathrm{~nm}$. This translated into a substantial increase in the distribution volume, a displacement of the accumulation mode radius towards greater radii and an increasingly evident spreading of the coarse-particle mode although maintaining the same radius as during the first period of the campaign.

Despite the intrusion of Saharan aerosols, the AOD values were not as great as might have been expected due to the closeness of the desert. One possible explanation is that the orographic boundary that is formed by the Atlas mountain range, and that separates the measurement area from the desert, retains air masses both on the side of the desert and on the side corresponding to the Atlantic influence. To determine this effect it would be necessary to analyse the aerosol characteristics from a spatially wider perspective perhaps based on the global treatment of MODIS images covering the whole region, from the Saharan desert to the Atlantic Ocean. However, during this time of year the intertropical convergence zone (ITCZ) is still fairly low, and only in certain conditions are intense dust advections produced. In their absence the atmosphere of the region remains clear, given the region's distance from industrialized or marine influences. 


\section{Acknowledgements}

The Marrakech WATERMED campaign was supported by ESA. We thank Dr Jauad El Karraz for the provision of MODIS imagery used in this publication, and NOAA Air Resources Laboratory (ARL) for provision of the HYSPLIT transport and dispersion model and/or READY website (www.arl.noaa.gov/ready.html) used in this publication.

\section{References}

Anderson, S.M. and Mauersberger, K., 1992, Measurements of ozone absorption crosssection in the Chappuis band. Geophysical Research Letters, 19, pp. 933-936.

Bodhaine, B.A., Wood, N.B., Dutton, E.G. and Slusser, J.R., 1999, On Rayleigh optical depth calculations. Journal of Atmospheric and Oceanic Technology, 16, pp. 1854-1861.

Chu, D.A., Kaufman, Y.J., Ichoku, C., Remer, L.A., Tanre, D. and Holben, B.N., 2002, Validation of MODIS aerosol optical depth retrieval over land. Geophysical Research Letters, 29, pp. 8007, doi:10.1029/2002GL013205.

DraXler, R.R. and RolPh, G.D., 2003, HYSPLIT (HYbrid Single-Particle Lagrangian Integrated Trajectory) (Silver Spring, MD: NOAA Air Resources Laboratory). Available online at: NOAA ARL READY website (www.arl.noaa.gov/ready/ hysplit4.html).

Estellés, V., 2006, Atmospheric aerosol characterization in Valencia by means of solar photometry. PhD thesis, Universitat de València, Valencia, Spain.

Estellés, V., Gómez-Amo, J.L., Marín, M.J., Pedrós, R., Utrillas, M.P. and MartínezLozAno, J.A., 2003, Analysis of performance of a Microtops II sunphotometer for ozone retrieval, in comparison with a Brewer spectrophotometer in Sodankylä, Finland. In Abstracts of the IX WMO/GAW Brewer Users Group Meeting.

Estellés, V., Martínez-Lozano, J.A., Utrillas, M.P. and Campanelli, M., 2007, Columnar aerosol properties in Valencia (Spain) by ground-based Sun photometry. Journal of Geophysical Research, 112, pp. D11201, doi:10.1029/2006JD008167.

Gómez-Amo, J.L., 2006, Atmospheric aerosol characterization in different climatic regions: Sodankylä, Barrax y Marrakech. PhD thesis, Universitat de València, Valencia, Spain.

Gómez-Amo, J.L., Martínez-Lozano, J.A., Utrillas, M.P., Pedrós, R. and Estellés, V., 2006, Column-integrated aerosol optical properties in Sodankylä (Finland) during the Solar Induced Fluorescence Experiment (SIFLEX-2002). Journal of Geophysical Research, 111, pp. D05202, doi:10.1029/2005JD006051.

GueYmard, C.A., 2001, Parameterized transmittance model for direct beam and circumsolar spectral irradiance. Solar Energy, 71, pp. 325-346.

Holben, B.N., Eck, T.F., Slutsker, I., Tanré, D., Buis, J.P., Setzer, A., Vermote, E., Reagan, J.A., Kaufman, Y.J., Nakajima, T., Lavenu, F., Jankowiak, I. and SMIRnmov, A., 1998, AERONET: a federated instrument network and data archive for aerosol characterization. Remote Sensing of Environment, 66, pp. 1-16.

Holben, B.N., Setzer, A., Eck, T.F., Pereira, A. and Slutsker, I., 1996, Effect of dry season biomass burning on Amazon basin aerosol concentrations and optical properties, 1992-1994. Journal of Geophysical Research, 101, pp. 19465-19481.

IPCC, 2001, Climate Change 2001: The Scientific Basis. Contribution of Working Group I to the Third Assessment Report of the Intergovernmental Panel on Climate Change, J.T. Houghton et al., (Eds), (New York: Cambridge University Press), p. 881.

Kasten, F. and Young, M.T., 1989, Revised optical air mass tables and approximation formula. Applied Optics, 28, pp. 4735-4738.

KING, M.D., 1982, Sensitivity of constrained linear inversions to the selection of Lagrange multiplier. Journal of Atmospheric Sciences, 39, pp. 1356-1369. 
King, M.D., Byrne, D.M., Herman, B.M. and Reagan, J.A., 1978, Aerosol size distribution by inversion of spectral optical depth measurements. Journal of Atmospheric Sciences, 35, pp. 2153-2167.

KöPPEN, W., 1918, A Klassifikation der Klimate nach Temperatur, Niederschlag und Jahreslauf. Patermanns Geographische Mitteilungen, 64, pp. 193-203.

Martínez-Lozano, J.A., Utrillas, M.P., Pedrós, R., Tena, F., Díaz, J.P., Expósito, F.J., Lorente, J., de Cabo, X., Cachorro, V., Vergaz, R. and Carreño, V., 2003, Intercomparison of spectroradiometers for global and direct solar irradiance in the visible range. Journal of Atmospheric and Oceanic Technology, 20, pp. 997-1010.

Mishchenko, M.I., Hovenier, J.W. and Travis, L.D., 2000, Light Scattering by Nonspherical Particles. Theory, Measurements and Applications (San Diego: Academic Press).

Morys, M., Mims, F.M., Hagerup, S., Anderson, S.E., Baker, A., Kia, J. and Walkup, T., 2001, Design, calibration and performance of Microtops handheld ozone monitor and sun photometer. Journal of Geophysical Research, 106, pp. 14573-14582.

Nakajima, T., Tonna, G., RaO, R. and Boi, P., 1996, Use of sky brightness measurements from ground for remote sensing of particulate polydispersions. Applied Optics, 35, pp. 2672-2686.

Pedrós, R., Martínez-Lozano, J.A., Utrillas, M.P., Gómez-Amo, J.L. and Tena, F., 2003, Column-integrated aerosol optical properties from ground-based spectroradiometer measurements at Barrax (Spain) during the Digital Airborne Spectrometer Experiment (DAISEX) campaigns. Journal of Geophysical Research, 108, pp. 4571, doi:10.1029/2002JD003331.

Remer, L.A. and Kaufman, Y.J., 1998, Dynamic aerosol model: Urban/industrial aerosol. Journal of Geophysical Research, 103, pp. 13859-13871.

Remer, L.A., Kaufman, Y.J., Tanre, D., Mattoo, S., Chu, D.A., Martins, J.V., Li, R.R., IchoKu, C., Levy, R.C., Kleidman, R.G., EcK, T.F., Vermote, E. and Holben, B.N., 2005, The MODIS aerosol algorithm, products, and validation. Journal of the Atmospheric Sciences, 62, pp. 947-973.

Remer, L.A., Tanre, D., Kaufman, Y.J., Ichoku, C., Mattoo, S., Levy, R., Chu, D.A., Holben, B., Dubovik, O., Smirnov, A., Martins, J.V., Li, R.R. and Ahmad, Z., 2002, Validation of MODIS aerosol retrieval over ocean. Geophysical Research Letters, 29, pp. 8008, doi:10.1029/2001GL013204.

Russell, P.B., Livingston, J.M., Dutton, E.G., Pueschel, R.F., Reagan, J.A., Defoor, T.E., Box, M.A., Allen, D., Pillewslie, P., Herman, B.M., Kinne, S.A. and Hofmann, D.J., 1993, Pinatubo and pre-Pinatubo optical depth spectra: Mauna Loa measurements, comparisons, inferred particle size distribution, radiative effects and relationship to Lidar data. Journal of Geophysical Research, 98, pp. 22969-22985.

Shaw, G.E., 1983, Sun photometry. Bulletin of the American Meteorological Society, 64, pp. 4-11.

Schmid, B., Mätzler, C., Heimo, A. and Kämpfer, N., 1997, Retrieval of optical depth and particle size distribution of tropospheric and stratospheric aerosols by means of sun photometry. IEEE Transactions on Geoscience and Remote Sensing, 35, pp. 172-182.

Sinyuk, A., Torres, O. and Duvovik, O., 2003, Combined use of satellite and surface observations to infer the imaginary part of refractive index of Saharan dust. Geophysical Research Letters, 30, pp. 1081, doi:10.1029/2002GL016189.

UtRILLAS, M.P., 1995, Estudio de aerosoles a partir de medidas de irradiancia solar espectral. $\mathrm{PhD}$ thesis, Universitat de València, Valencia, Spain.

van Der Hulst, H.C., 1957, Light Scattering by Small Particles (New York: John Wiley \& Sons).

Yamamoto, G. and Tanaka, M., 1969, Determination of aerosol size distributions from spectral attenuation measurements. Applied Optics, 8, pp. 447-453. 